\title{
Strategy Based Instruction Facilitated by Technologies to Enhance Reading Comprehension
}

\author{
Miguel A. Ochoa \\ Universidad Estatal de Sonora/Licenciatura de Enseñanza del Inglés, Hermosillo, México \\ María S. Ramírez \\ Tecnologico de Monterrey/Escuela de Educación, Humanidades y Ciencias Sociales, Monterrey, México
}

\begin{abstract}
This study was set to determine the level of reading comprehension achievement for university students when instructed cognitive and metacognitive strategies in a learning environment mediated by technologies. Accordingly, the paper tried to answer this research question: Which is the effect of using cognitive and metacognitive strategies in a technology enriched environment on students to achieve the B1 English proficiency level according to the Common European Framework of Reference (CEFR) in reading comprehension? This study took place in Universidad Estatal de Sonora (UES), México through a sequentialexplanatory mixed method research design which focused on a sample of 96 students who received 15 hours of instruction in Language Learning Strategies (LLS) by 6 teachers. A reading comprehension pre-test/post-test, a self-reported questionnaire in the use of cognitive and metacognitive strategies, a semi-structured interview and document analysis were used to gather data. For data analysis, a paired samples t-test technique and a phenomenological approach were conducted to analyze quantitative and qualitative data, respectively. The study showed contrasting results given that the reading comprehension test reflected low scores even though the students developed a better understanding of cognitive and metacognitive strategies and an improvement in their reading comprehension skills in class.
\end{abstract}

Index Terms—-technology, reading comprehension, cognitive strategies, metacognitive strategies

\section{INTRODUCTION}

An effective instructional class design plays a significant role in positively affecting the teaching and learning process through addressing key elements such as the students' different learning styles and previous academic experiences and knowledge. Consequently, cognitive processes and behavioral changes in students can be enhanced by the instruction and use of learning strategies in class as well as effective classroom management and the creation of a stimulating environment which promotes active participation and openness to opinions. In that sense, the teacher's critical understanding of learning strategies applied effectively to language learning in class can lead to a more satisfying academic success. Rahimi \& Katal (2011, p. 1) defined learning strategies as "techniques for understanding, reminiscence and use of information that is intentionally used and consciously controlled by the learner". Furthermore, Oxford (2003) represented them as steps, actions, behaviors, or techniques used by students to enhance their own learning, that is, to make it easier, faster, enjoyable, self-directed, effective and transferable to new situations. In sum, learners may have metacognitive knowledge about their own thinking and learning approaches, a good understanding of what the activity or task involves and the ability to come up with cognitive strategies that best meet the demands of the assignment and their own learning strengths.

Additionally, the use of multimedia learning materials or technological devices to heighten the instructional content of LLS in class can mean a whole different approach to achieving the learning goals insomuch as it may prove a more significant and enjoyable learning journey and experience. In that sense, Web-based technologies, the powerful Internet connections and multimedia learning materials provide a wide range of possibilities to the development of educational technology that supports flexible, well-designed, efficient, interactive, affordable, and student's cantered e-learning environments (Sarica \& Cavus, 2009). The result will be an English language learning that is more enjoyable and easier.

English communicative skills, specifically reading comprehension, can benefit a great deal from taking all of these elements into account while developing it effectively in English as Foreign Language (EFL) students or no-native speakers of the language. According to Suwantharathip (2012), the reading comprehension abilities are necessary to acquire knowledge and learning of new information, especially for those students who want to study at the university. To better understand a text, he argued that students use two main strategies: cognitive and meta-cognitive strategies. (C) 2016 ACADEMY PUBLICATION 
Moreover, Nejabati (2015) argued that "reading comprehension is assumed to be the ability to construct meaning before, after and during reading through linking reader`s background knowledge and the presented information by the author in the context”. (p. 1345). 
In conclusion, the all-around purpose to integrate strategy based instruction (SBI) in a technology enriched environment to enhance reading comprehension skills may bear bruit since it has been shown time and again that proficiency levels accomplishments in Mexico's Public Educational System and, specifically, in higher education remain scarce at best. According to the Mexico's Minister of Education (Secretaria de Educacion Pública, 2016), about 150,000 teachers from elementary to post-secondary public schools were evaluated on the basis of teacher performance in November and December 2015. The subject in which teachers’ performance results were the worst was English. A little more than half of the English teachers evaluated got an insufficient note. It is thus recognized that the Mexican State has never invested in ELT in a sound and consistent manner and with a strategic plan. Finally, the purpose of this mixed-method study is to determine the level of reading comprehension for EFL university students with a level of proficiency B1 according to the CEFR that can be achieved when instructed cognitive and metacognitive strategies in a technology enriched environment.

\section{LITERATURE REVIEW}

The instruction and use of language learning strategies has become common household in nowadays English classrooms. According to Xu (2011, p. 204), "learning strategies have been extensively employed in the educational field because of its significance”. Meanwhile, Motallebzadeh \& Mamdoohi (2011) claimed that LLS contribute to facilitating the process of acquisition, storage, retrieval, and use of information in students' learning through operations and procedures that they employ. On the other hand, Strategy Based Instruction (SBI) advocates an approach that enables students not only to get the gist of what can be learned in class, but also how it can be learned more appropriately. Motallebzadeh \& Mamdoohi (2011, p.3) argue that SBI "helps learners become more aware of what kinds of strategies are available to them, understand how to organize and use strategies systematically, and learn when and how to transfer the strategies to new language learning and using contexts”. What's more, Chamot (2004) pointed out that the explicit instruction of LLS consisted of students' realization of the strategies they commonly use and those new and potentially helpful to them, teacher modelling of critical thinking, student self-evaluation of the strategies used, and transferring strategies to new tasks. Consequently, students must exercise a critical thinking process in order to determine what exactly they intend to do or learn, how to do or learn it, that is, the specific actions to be taken to achieve those goals related to language learning. In other words, students should be able to select appropriate learning LLS according to what best fits their learning styles so as to develop a set of skills that will make them more autonomous, self-directed and responsible of their own learning.

According to different kind of taxonomies of strategies to language learning defined by a series of respected researchers on the matter, there is one-O’Malley’s Classification of Language Learning Strategies- which classifies it in three main categories: Cognitive, metacognitive and socioaffective strategies (Zare, 2012). Pham (2011) defines cognitive strategies as a control and internal process by which learners select and modify their ways of attending, learning, remembering, and thinking, that is, developing internal processes that enable them to perform complex tasks. Besides, Kasimi (2012, p. 162) claims that "cognitive strategies help students form and revise internal mental models and receive and produce messages in the target language with a conscious manner”. On the other hand, Wichadee (2011) defines metacognitive strategies as effective tools which make learners consciously aware of what learning has taken place and recognize situations in which that learning could be of use. Iwai (2011) extends on classifying metacognition into four categories: knowledge, self- experience, assignments, and actions or strategies to be applied. The regulation of cognition refers to planning, monitoring and evaluating different strategies in order to get the most adequate for a specific reading task. In sum, metacognitive instruction has a positive influence when students and teachers try to improve reading comprehension.

Multimedia instructional contents can be designed with relative ease through the use of a Microsoft PowerPoint application which has an enormous potential to positively impact in student's learning. A PowerPoint presentation facilitates a smooth and easy class flow and provides a defined structure. (Lai, Tsai \& Yu, 2011). On the other hand, the production of Open Educational Resources (OER) allows the development of competencies related to the use of technology and their integration in instructional contents. In that sense, Ramirez (2013) describes the OER as a series of materials, resources, elements or multimedia and textual applications to be integrated into virtual or traditional learning environments. Furthermore, they feature a free license given by the author him/herself. In sum, both technologies provide tangible benefits for students' learning when their use is optimized.

According to Alharbi (2015), "The ability to read and comprehend efficiently is essential for meeting the needs of everyday life as well as for success in the academic arena” (P.1257). In that sense, reading is one of the most important skills in the process of acquiring or learning a second language such as English. Both culture and reading strategies are strongly related in the development of successful text comprehension (Kasimi, 2012). Explicit reading strategies have a positive impact when the purpose is to improve reading proficiency, so teachers must include them in the development of a Reading second language class (Aghaie and Zhang, 2012). In that sense, Chellamani (2013) emphasizes the importance of teaching metacognitive strategies for students so reasoning may represent a difference of successful development when reading in the target language.

As said by Tezcan and Deneme (2016), so much research has been conducted on LLS attempting to identify how the use of these strategies provide an efficient language teaching and learning process. In that sense, a study conducted by 
Motallebzadeh and Mamdoohi (2011) explored the effects of LLS on students' performance through a non-intensive TOEFL training program with emphasis in developing reading comprehension skills in which an experimental group received SBI instruction while a control group a traditional one. The results showed that the experimental group significantly outperformed the control group, heightening the use of cognitive strategies as those with greater effect on improving reading comprehension. It also concluded that the teacher should encourage those less competent students to imitate and practice the strategies used by the more skilled ones through constant practice.

Likewise, Marzban (2011) conducted a study that compared the effects of articles written by using multimedia technologies with those based on paper, both on reading comprehension. 68 EFL pre-intermediate students from northern Iran participated in the study. The results showed superiority when combining audio, video and photographs compared with only text when new knowledge was presented. Nevertheless, it concluded that the merits of using multimedia technologies could be affected, to a large degree, by the many obstacles teachers faced during its handling such as infrastructure problems, lack of training on technologies, a teacher centered approached, weak technical support and the use of workbooks. Finally, Nacera (2010) conducted a study to evaluate the use of LLS by second-year students from Mouloud Mammeri University in Argelia, while acquiring and expanding new vocabulary in English through measuring their basic knowledge of word meaning. The results showed that the students used a wide range of direct and indirect strategies, being the metacognitive the most employed. Additionally, the strategies more commonly used by students with an extensive repertoire of vocabulary were summarizing, inferring and predicting, all of those in a combined form.

\section{RESEARCH QUESTION}

The study took place in Universidad Estatal de Sonora, a higher education institution that is located in the state of Sonora, México and holds 18 different majors of fields of study throughout its five main Campus. English, in that sense, is a curricular basic subject which is taught through the first four semesters. The study focused on regular students with an A2 English proficiency level, according to CEFR, coming from several majors. On the other hand, developing reading comprehension skills is essential if learners want to follow higher studies. Unfortunately, it has been shown that most students in Mexican public universities do not have sufficient reading comprehension skills to undergo graduate or postgraduate education. According to a study conducted by the National Association of Universities and Higher Education Institutions (ANUIES) in Mexico between 2001 and 2002, all the first-year college students from nine Mexico City higher institutions underwent a test on English communicative skills to measure their language proficiency. The results showed a grim picture of the situation. Almost all of the students failed the test with very low marks (Secretaria de Educacion Pública, 2006). Consequently, the need to support higher education to achieve reading comprehension competencies in level B1 has been identified through this investigation. To contribute to the educational scientific field, the following research question was formulated: Which is the effect of using cognitive and metacognitive strategies in a technology enriched environment on students to achieve the B1 English proficiency level, according to CEFR in reading comprehension?

\section{METHOD}

\section{A. Participants}

The convenience non-probabilistic sampling technique, which selects a participant sample of the population based on their accessibility, acquisition and availability to the researcher, was used to select the participants (Battaglia, 2008). The sample included six groups of 16 students on average, that is, 96 students (63 women and 33 men) which belonged to three different majors (International Commerce, Tourism and Sports Training) and voluntarily accepted to participate. In addition, six teachers from each group (three women and three men) were included. All participating English teachers had at least a Teaching Knowledge Test (TKT) certificate from Cambridge University and more than five years of teaching experience. Additionally, the students were registered in a curricular intermediate English -B1 proficiency level- subject or class in the fourth semester and had an A2 English proficiency level according to CEFR. They were formally invited to participate in the study through the signing of an informed consent letter and were notified of the investigation procedure before starting the data collection. The students' age range was between 19 and 23 years old.

\section{B. Instruments}

An EFL reading comprehension pre-test and post-test was administered to the students before and after the SBI to evaluate the impact of the use of cognitive and metacognitive strategies meditated by technologies on enhancing reading comprehension competences. Additionally, a self-reported questionnaire in the use of cognitive and metacognitive strategies was applied by the learner's at the end of the course. Also, a semi-structure interview was conducted with teachers to get an overall sense of their experience through the investigative process. Finally, document analysis through a students' progress reflections format posted in an e-portfolio was executed in order to find out their feelings towards the use of reading strategies to improve reading comprehension.

\section{Procedure}


The study took place in an EFL classroom where the researcher was an active participant as the English class teacher alongside his fellow five peers. The students had two and a half hours a week for six weeks of instruction in LLS (cognitive such as visualizing, making connections, predicting, re-reading, summarizing, using text structure, thinking- aloud and using visual representations of text; and metacognitive such as planning, monitoring and evaluating) mediated by technology such as PowerPoint (PP), OER and E-Portfolio. The students underwent several text passages a week which highlighted the use of two different reading strategies per passage. Teachers explicitly taught how the strategies work, in which context they should be applied, and how to use them, all by using PP presentations and drilled through OER on their own personal computer. Additionally, the students' learning reflections were posted through a graphical organizer known as K-W-L (acronym for what students Know, Want to know and Learned) chart in their e- portfolio. Finally, the teacher was prompt to make suggestions in how to choose the strategies effectively, that is, by taking their own learning styles and preferences into account while they were working on the text. At the end of each learning activity, the teacher also gave sound feedback and sensibly corrected any mistake where needed.

\section{The Design of the Study}

Mixed methods combine qualitative and quantitative approaches in order to explain and describe a phenomenon. Burke Johnson \& Onwuegbuzie (2004) define it as an inclusive, pluralistic and complementary method in which the researcher takes an eclectic approach to the selection of the method and conduction of the study. According to the different types of mixed methods research designs, a sequential-explanatory was selected to conduct this study. According to the nomenclature commonly used in mixed methods research, a QUAN qual was us $\rightarrow$ This means that obtaining quantitative data has a prominence and is executed in a sequential manner. That is, once this method is completed, the qualitative is performed, indicating that the use of the qualitative method is executed mainly to complement the analysis of the quantitative method (Tashakkori \& Teddlie, 2010).

\section{FINDINGS AND RESULTS}

\section{A. Inferencial Statistic of the EFL Reading Comprehension Exam}

In order to establish the existence of significant changes in reading comprehension achievement for 96 students after being instructed on cognitive and meta-cognitive strategies mediated by technology, the following null hypothesis is presented: There is no significant changes in scores from pre- and post-test (reading comprehension exam) for students after participating in a SBI course mediated by technologies. In order to validate the quantitative instrument, it was decided to use an existing reading examination format, sufficiently tested in various contexts and institutions of higher education with safe levels of validity and reliability (Liu, 2009). In short, this instrument is validated by itself for its application in field work because of its wide experience applicability in various studies on the development of reading comprehension skills in the university context.

A paired sample t-test was performed to confirm or reject the null hypothesis as well as determine whether the t-test was significant. Then, tables 4.1 and 4.2 related to this analysis are presented:

TABLE 4.1

PAIRED SAMPLE STATISTICS OF THE EFL READING COMPREHENSION EXAM

\begin{tabular}{clllll}
\hline & & Mean & N & Std. Deviation & Sd. Error Mean \\
\hline \multirow{2}{*}{ Pair 1 } & Pretest & 14.30 & 96 & 7.236 & .739 \\
\cline { 2 - 6 } & Posttest & 15.66 & 96 & 7.387 & .754 \\
\hline
\end{tabular}

TABLE 4.2

PAIRED SAMPLE TESTS OF THE EFL READING COMPREHENSION EXAM

\begin{tabular}{|c|c|c|c|c|c|c|c|c|}
\hline & \multicolumn{5}{|c|}{ Paired Differences } & \multirow[t]{3}{*}{$\mathrm{t}$} & \multirow[t]{3}{*}{$\mathrm{df}$} & \multirow{3}{*}{$\begin{array}{l}\text { Sig. } \\
\text { (bilateral) }\end{array}$} \\
\hline & \multirow[t]{2}{*}{ Mean } & \multirow[t]{2}{*}{$\begin{array}{l}\text { Std. } \\
\text { Deviation }\end{array}$} & \multirow[t]{2}{*}{$\begin{array}{l}\text { Sd. Error } \\
\text { Mean }\end{array}$} & $\begin{array}{l}95 \% \mathrm{Cc} \\
\text { of the d }\end{array}$ & $\begin{array}{l}\text { ce interval } \\
\text { ce }\end{array}$ & & & \\
\hline & & & & Lower & Upper & & & \\
\hline Pair 1 Pretest - Posttest & -1.354 & 6.237 & .637 & -2.618 & -.090 & -2.127 & 95 & .036 \\
\hline
\end{tabular}

A paired sample t-test was conducted in order to assess whether there was a statistically significant difference between mean scores of pre- and post-test (reading comprehension exam) before and after an SBI course mediated by technologies. The test indicated the absence of violations to assumptions. The results of the paired sample t-test were significant, $t$ (95) $=2.127, \mathrm{p}<.05, \mathrm{n} 2=.05$, indicating a significant increase in test scores in reading comprehension pretest $(\mathrm{M}=14.30$, $\mathrm{SD}=7.236, \mathrm{~N}=96)$ to posttest $(\mathrm{M}=15.66, \mathrm{SD}=7.387)$. The effect size was small, Cohen's $\mathrm{d}$ $=.22$, based on Cohen conventions (Cohen, 1988). The mean increase was 1,354, with 95\% of confidence interval for the difference between the means of .090 to 2618. In conclusion, the researcher rejects the null hypothesis.

\section{B. Descriptive Statistic of the Self-reported Questionnaire in the Use of Cognitive and Metacognitive Strategies}

In order to understand the nature of the strategies used by learners in the resolution of a reading comprehension test, this study adopted and translated into a Spanish a self-reported questionnaire format on the use of cognitive strategies 
and meta-cognitive in Likert-scale from Phakiti (2003). The questionnaire allowed evaluating, out of 30 items, the frequency in which the different types of strategies were used. For this purpose, a descriptive statistical analysis was made. The validation of the cognitive and metacognitive strategies constructs of the instrument were based on a number of itemlevel analysis (Phakiti, 2003). Cognitive strategy factors included comprehending, memory and retrieval strategies. On the other hand, the metacognitive strategy factors had to do with planning, monitoring, and evaluating strategies. The descriptive statistics for 30 observed variables are presented in Tables 4.3 and 4.4. The items could be considered normally distributed. All variable skewness and kurtosis statistics were within the acceptable limits, which was suggestive of univariately normal distribution. The following statistical tables 4.3, 4.4 and 4.5 related to the analysis and report of results are presented:

TABLE 4.3

DESCRIPTIVE STATISTICS OF COGNITIVE STRATEGIES

\begin{tabular}{|c|c|c|c|c|c|}
\hline Strategies & $\begin{array}{l}\mathrm{N} \\
\text { Stats }\end{array}$ & $\begin{array}{l}\text { Mean } \\
\text { Stats }\end{array}$ & $\begin{array}{l}\text { SD } \\
\text { Stats }\end{array}$ & $\begin{array}{l}\text { Skewness } \\
\text { Stats }\end{array}$ & $\begin{array}{l}\text { Kurtosis } \\
\text { Stats }\end{array}$ \\
\hline 1. I made short notes or underlined main ideas during the test. & 96 & 2.11 & 1.055 & 1.085 & .780 \\
\hline 2. I translated the reading texts and tasks into Spanish & 96 & 3.14 & 1.166 & .056 & -.963 \\
\hline 3. I used pictures or titles of the text to help comprehend reading tasks. & 96 & 3.93 & 1.098 & -.926 & .470 \\
\hline 4. I used my own English structure knowledge to comprehend the text. & 96 & 3.53 & 1.222 & -.233 & -1.202 \\
\hline 5. I spend more time in difficult questions. & 96 & 3.68 & 1.061 & -.451 & -.584 \\
\hline $\begin{array}{l}\text { 6. I tried to understand the texts and questions regardless of my vocabulary } \\
\text { knowledge. }\end{array}$ & 96 & 3.77 & 1.041 & -.496 & -.657 \\
\hline 7. I tried to find topics and main ideas by scanning and skimming. & 96 & 2.90 & 1.031 & .213 & -.631 \\
\hline 8. I read the texts and questions several times to better understand them. & 96 & 3.91 & 1.179 & -.837 & -.281 \\
\hline 9. I used my prior knowledge to help understand the reading test & 96 & 3.90 & .968 & -.571 & -.282 \\
\hline 14. I attempted to identify main points of the given Reading texts and tasks. & 96 & 3.56 & 1.024 & -.352 & -.543 \\
\hline $\begin{array}{l}\text { 22. I tried to understand the questions adequately before attempting to find } \\
\text { the answers. }\end{array}$ & 96 & 4.21 & .917 & -1.015 & .200 \\
\hline 26. I used multiple thinking strategies to help answer the test questions. & 96 & 3.48 & 1.114 & -.389 & -.330 \\
\hline $\begin{array}{l}\text { 29. I selected relevant information to help me understand the reading texts } \\
\text { and answer the test questions. }\end{array}$ & 96 & 3.54 & 1.123 & -.470 & -.454 \\
\hline
\end{tabular}

TABLE 4.4

DESCRIPTIVE STATISTICS OF METACOGNITIVE STRATEGIES

\begin{tabular}{|c|c|c|c|c|c|}
\hline Strategies & $\begin{array}{l}\mathrm{N} \\
\text { Stats }\end{array}$ & $\begin{array}{l}\text { Mean } \\
\text { Stats }\end{array}$ & $\begin{array}{l}\text { SD } \\
\text { Stats }\end{array}$ & $\begin{array}{l}\text { Skewness } \\
\text { Stats }\end{array}$ & $\begin{array}{l}\text { Kurtosis } \\
\text { Stats }\end{array}$ \\
\hline 1. I tried to identify easy and difficult test tasks. & 96 & 3.74 & 1.136 & -.746 & -.124 \\
\hline $\begin{array}{l}\text { 2. When I started to complete the test, I planned how to complete it and } \\
\text { followed the plan. }\end{array}$ & 96 & 2.83 & 1.158 & .125 & -.771 \\
\hline 3. I was aware of what and how I was doing in the test. & 96 & 4.07 & .997 & -.734 & -.607 \\
\hline 4. I checked my own performance and progress while completing the test. & 96 & 3.45 & 1.160 & -.202 & -.903 \\
\hline $\begin{array}{l}\text { 15. I thought through the meaning of the test tasks/questions before } \\
\text { answering them. }\end{array}$ & 96 & 3.63 & 1.039 & -.112 & -1.150 \\
\hline 16. I was aware of which strategy to use and how and when to use it. & 96 & 3.45 & 1.025 & -.036 & -.883 \\
\hline 17. I corrected mistakes immediately when found. & 96 & 3.79 & 1.104 & -.533 & -.668 \\
\hline $\begin{array}{l}\text { 18. I asked myself how the test questions and the given texts related to what I } \\
\text { already know. }\end{array}$ & 96 & 3.51 & 1.036 & -.405 & -.425 \\
\hline 19. I determined what the test tasks/questions required me to do. & 96 & 3.72 & 1.013 & -.338 & -.693 \\
\hline 20. I was aware of the need to plan a course of action. & 96 & 3.11 & 1.150 & -.186 & -.657 \\
\hline 21. I was aware of how much the test remained to be completed. & 96 & 4.05 & .988 & -.775 & -.156 \\
\hline 23. I made sure I understood what had to be done and how to do it. & 96 & 4.05 & .875 & -.584 & -.431 \\
\hline 24. I was aware of my ongoing Reading and test taking. & 96 & 3.98 & .917 & -.543 & -.565 \\
\hline 25. I kept track of my own progress to complete the questions on time & 96 & 3.40 & 1.138 & -.482 & -.497 \\
\hline 27. I made sure to clarify the goal and know how to complete it. & 96 & 3.63 & 1.018 &,- 286 & .200 \\
\hline 28. I checked my accuracy as I progressed through the test. & 96 & 3.64 & 1.037 & -.429 & -.514 \\
\hline 30. I carefully checked the answers before submitting the test. & 96 & 4.08 & .970 & -.665 & -.752 \\
\hline
\end{tabular}

TABLE 4.5

DISTRIBUTIONS FOR VARIABLES USING COGNITIVE AND METACOGNITIVE STRATEGIES

\begin{tabular}{lll}
\hline Variable & Mean & Standard Deviation \\
\hline Cognitive strategies & 3.51 & 1.077 \\
Metacognitive strategies & 3.65 & 1.045 \\
\hline
\end{tabular}

The interpretation of a mean score guide in relation to the strategy used by the student to do an exercise or reading comprehension test indicates that an elevated use of a strategy will indicate a mean of 3.5 or higher, a moderate use will indicate a mean between 2.5 to 3.4, and low use a mean of 2.4 or less (Mokhtari and Reichard, 2002). In table 6, the results of the analysis are shown in terms of the mean scores obtained in carrying out the questionnaire of the use of cognitive and metacognitive strategies after completing the EFL reading comprehension test.

In that sense, it can be seen that both types of strategies are used with high mean frequency (3.51 for cognitive and 3.65 for metacognitive, respectively), being the cognitive memory strategies $22(\mathrm{M}=4.21, \mathrm{SD}=.927)$, related to trying 
to understand the questions adequately before attempting to find the answers and $8(\mathrm{M}=3.91, \mathrm{SD}=1.179)$, related to repeatedly read the texts and questions to better understand them; and cognitive understanding $3(M=3.93$, $S D=1.098)$ related to using photographs or titles of the texts to help understand reading tasks, as the most used by the participants. Also, the metacognitive evaluation strategies $30(\mathrm{M}=4.08, \mathrm{SD}=0.970)$, related to carefully reviewing the answers before submitting the exam,; and metacognitive monitoring $12(\mathrm{M}=4.07, \mathrm{SD}=.997)$ related to being aware of what and how a student was doing in the test, and $21(\mathrm{M}=4.05, \mathrm{SD}=.988)$ related to being aware of how much the test remained to be completed were among the ones with the highest average.

\section{Phenomenological Approach to Semi-structured Interviews}

A phenomenological approach was used to analyze the transcripts of teachers' semi-structure interviews. Out of six transcripts, 48 significant statements were extracted from the lived experience of teachers facilitating the learning and use of language strategies in a technology enriched environment to improve reading. Every significant statement was reduced to 12 formulated meanings. Consequently, the formulated meanings were clustered resulting in 4 themes common to all of the participants' transcripts. In order to validate the final findings, the researcher approached some participants once again to prove their sayings or conclusions. The results of these topics are presented below:

Theme 1. Expectations and positive effects on strategy instruction. A number of considerations about SBI are reflected in this interview with the views of many teachers, who noted an improvement in the aspects of utility; better learning opportunities, specifically effective reading comprehension and their possible application in other disciplinary areas. Also, one respondent noted that the SBI teachers, "offer the possibility to identify what best suits their learning needs and level of understanding, and enhance their capacity and scope in the development of activities with the expectation of better results”. About the effects that SBI has on students, the respondents asseverated an effective assimilation of the information, a much wider range of options offered more quickly and effective and better attention given by students during the development of several learning activities, "in a specific class we find multiple intelligences and diverse and varied learning styles. Thus, the effects will become better and more positive because they are covering the various types of students' learning".

Theme 2. Critical thinking through the different cognitive strategies. Specifically in the strategy of asking questions, one of the teachers interviewed explained the range of possibilities offered by making judgmental opinions about the reading, where students can increase their knowledge about the issue in the text and relate it directly to the context in which they are immersed, "when the student/reader raises certain questions about the information in a text, he/she is forming his/her own view on it". The strategy of making predictions or inferences about the text, a set of perceptions through which teachers promote the practice of critical reading based on previous knowledge of the student was raised. The student somehow tries to interpret or deduce the situations contained in the text. Also, by predicting, students are intended to put aside consideration of right or wrong answers, "there are no right and wrong answers, they are just your predictions, what you think to be or go, and just express it "said one of the teachers.

Critical thinking by clarifying certain ideas contained in the text and/or making connections between reading and personal experiences or events in the world contribute to the expansion of vocabulary and improving knowledge. The students themselves are the ones who help to clarify the doubts about the reading. Furthermore, making connections between prior knowledge and new information, that is, from their own experience with a specific reading leads to relate the content of the text with the student's environment or real situations, "It's important that they relate all the knowledge they bring to the reading ... how they can give an opinion if they do not know what they're talking about. Then, when they make connections maybe they watched something on television, in Spanish, and they have now an idea in English”. Through visualization, teachers focused on mentioning various techniques which, on their own experience, have allowed a deeper understanding of the text through recreating mental images, producing "mental movies" and achieve the objectives previously outlined in the activity of reading, "visualizing is essential ... the use of imagination is basic, if you can visualize something, you can achieve it, if you can see it you can do it, it's something that I tell my students," declared one of the teachers.

Theme 3. Impact of meta-cognitive strategies in reading comprehension and its phases. In the first phase of implementing metacognitive strategies, which is planning, teachers said that these are useful to see what is going to be read from the information contained in the text, as well as the selection of interesting topics for the students. A teacher argues that "analyze the title, illustrations, key words, think about what the student would be interested on and wants to know about the topic, so human mind is predisposed to try to deepen in the acquisition of knowledge". In the second phase of monitoring, teachers say they use different cognitive strategies such as visualization, re-reading, cause and effect, among others. At the same time, they relate the topic of reading with issues of current interest for students- readers, "to predict the information on text, make connections between previous knowledge and the reading, make inferences, to use certain features of the context of the text itself." The third and final phase of meta-cognition, evaluation, teachers argued discrimination between the strategies which were successfully applied according to the teacher's and student's perception, from those whose implementation was far from being a significant difference, "when the reading is done, we reflect on the strategy followed, which was applied for understanding. If it works, great; if not, we must see what was wrong in order to change it".

Theme 4. Technological resources and contributions in the course instruction and the evaluation of competences. Teachers reported that the computer, the Internet, the projector, and the audio have a great impact on learning in the 
classroom, Also, OER can mean a very significant advance through the appropriate facilitator's guide, "to properly use technologies during the EFL teaching-learning process, it entails that the student had diverse and varied resources. All of this won't be possible if the instruction and the facilitator's guide are not the appropriate ones”. On the other hand, the eportfolio contributed significantly to the evaluation of students' competences, showing information such as a description of the contents of the text using own ideas and/or concepts, "the development of competences is daily seen in the classroom". Also, the use of reliable tools in the development of teaching-learning process of reading comprehension, as noted one of the teachers, is essential, "the combination of electronic portfolios with what takes place in the process of teaching-learning would be essential to determine its success”.

\section{Phenomenological Approach to Document Analysis}

The same phenomenological method was used to analyze the reflections of eight students (four outstanding students and four under average) in a K-W-L format. Out of eight transcriptions, 32 meaningful statements were extracted from the lived experience of some students who were exposed to LLS in a technology enriched environment to improve reading. Every meaningful sentence was reduced to 8 formulated meanings. Consequently, the meanings formulated were clustered resulting in 2 themes common to the entire sample of participants' transcripts. In order to validate the final findings, the researcher approached some participants once again to prove their sayings or conclusions. The results of these topics are presented below:

Theme 1. Impact of cognitive and meta-cognitive reading comprehension strategies in reading comprehension. In this section, students reported to understand a specific text more meaningfully, choose the strategies that best adapt to their learning styles, be more independent in their development of reading comprehension, and to be able to apply and use the different cognitive and meta-cognitive strategies, "the truth is that I have read a little bit better and personally I understood more all the contents of the sections we've had," said one student. Another of the students said: "I understand the reading very well, it wasn't so difficult and I could apply the strategies of predicting and making connections in order to remember things that I have experienced to and belong to reading, I like this strategy”. When using meta-cognitive strategies, students were able to auto-evaluate themselves and reflect on those strategies that worked better for them, so they can use them during the reading. It also allowed them to become aware of what to do before (planning) starting a reading and get the main idea through visualizing headers, drawings, summary reports, graphics, illustrations, among others, as well as during the development (monitoring) of the activity and adapt what was necessary, "I will reflect and remember what I have read by applying and remembering the strategies that I applied in the texts, how I applied each strategy".

Theme 2. The impact of technology in teaching-learning process. The resources with a greater impact in learning were the Internet and PowerPoint (PP) since the first one represents a tool with a wide range of use and the second a variety of content anytime, anywhere, "I can use the Internet at home and somewhere else, and search what I need. It is a big thing that I can use it for my classes, it is very fun and dynamic", said one of the students. On the other hand, technologies such as OER and PP are widely recognized as important tools in the teaching-learning process, but might be frustrating if not used comprehensively and with a clear objective, "at first, it was pretty fun to see a class with so many images and videos during the presentations, but then it became monotonous and predictable. Always the same way of presenting things...” said some students. Finally, the e-Portfolios contribute to the students themselves in order to reflect about their own advance, learning and areas to improve, as well as providing an opportunity to constantly monitor their own development through representative evidence of their progress, "the portfolio seems a good way to have what I did in the classroom and in the English subject, see where I was wrong and how I can improve”, said one student.

\section{DISCUSSION AND IMPLICATIONS}

The comprehensive analysis of data collected through quantitative and qualitative instruments showed a somehow moderate relationship between instruction/use of cognitive and metacognitive strategies and the improvement of reading comprehension skills. According to Table 2, there was a significant increase in test scores in reading comprehension pretest $(M=14.30, S D=7.236)$ to posttest $(M=15.66$, $S D=7.387)$. Also, Table 6 indicated the use of language learning strategies by learners in an elevated average frequency (3.51 to 3.65 for cognitive and metacognitive) in reading comprehension activities. However, the mean scores of pre-test and post-test represent a far from satisfactory performance when contrasted in terms of the number of test items (40). Prior knowledge of a certain level of proficiency in English language plays an important role in the development of the ability of reading comprehension. In this sense, Lin (2002, p.172) states the significance of prior knowledge of the competent reader as a "crucial knowledge for reading, which is categorized into two types: the knowledge of how and knowledge of substance." In short, the result of pre-test and posttest perhaps was related to factors other than the use of strategies such as their level of language proficiency, the method of examination, etc.

Although the students showed a lack of knowledge and practice in the use of learning strategies in class at the beginning of the study, an improvement in their performance was experienced as soon as there was an immersion in the subject. According to the data from interviews and reflections of students, one teacher said, "visualizing is essential .... the use of the imagination is basic, if you can visualize something, you can do it, and if you can see it you can do it”. 
Meanwhile, a student said "the meta-cognitive strategy of planning allows us to get the main idea of the text by making reviews derived from headers, drawings, summary reports, graphics, etc. ...” Also, one of the cognitive strategies whose frequency of use was the highest, according to Table 4 , was the number three $(M=3.93, S D=1.098)$ which is related to the use of photographs or titles to help with the reading comprehension. In that sense, Motallebzadeh and Mamdoohi (2011, p.3) argue that SBI "helps students become more aware of what kind of strategies are available to them, how to organize and use them systematically, and learn when and how to transfer them to new contexts for language learning". This probably means that a meaningful learning may have taken place even though the performance on the test showed the opposite due to an arguably number of other factors different from the variables considered.

Finally, technologies, in particular e-portfolio, improved the student's meta-cognition when exercising constantly their critical thinking during the reading analysis reflected in the K-W-L charts. According to the themes of the interviews and reflections, the electronic portfolio contributed significantly to the evaluation skills of students in terms of describing contents of the text using ideas and/or own conceptions. It also allowed students to reflect on their own progress, learning and areas that can be improved, as well as providing an opportunity to constantly monitor their own development through representative evidence of their performance, "the portfolio seems like a good way to keep what I did in class, see what was wrong and how I can improve, "said one student. In this sense, Lin, Yang and Lai (2013, p.18) argue that e-portfolios "improve student's personal development and assist them on their evaluation skills in a studentcentered educational context." It also facilitates the learner handling of their own learning process and allows the educator to observe and evaluate the student's progress from the collected evidence. In short, we conclude that electronic portfolios are thoughtful and helpful, besides being an excellent means of linking theory with practice.

In general terms, the reading comprehension test results were slightly negative, although a significant increase was experienced in terms of differences in average scores between the pre-test and post-test. However, such overall low marks can be explained for the learner's poor knowledge or low proficiency in the language level to be assessed. In other words, proper competence plays a decisive role in the effective implementation of a test because even if the reader is aware of the implications of the task, maybe he/she is not able to achieve an optimal performance when they lack relevant language skills according to the level task. In that sense, this factor of linguistic competence may be the language skills that obstruct cognitive and metacognitive learning in order to reach the B1 level, according to the CEFR for reading comprehension. In other words, teachers should work on improving students' language proficiency while exercising LLS during reading tasks in order to achieve better leanings and test performance.

On the other hand, the students developed a better understanding of cognitive and metacognitive strategies, and their reading comprehension improved significantly. Conducting this research practice was very pleasant, since we observed students have a better perspective of the text while using a combination of LLS in class, so from a pedagogical standpoint it would be a meaningful learning experience to comprehensively integrate SBI in every teacher's curriculum and teaching practice given that it contributed tothe student's exercise of critical thinking.

Even though the use of information and communication technologies (ICT) such as PP and OER in class represented a novel concept and was recognized as facilitating tools to the creation of a significant learning environment during the strategy based instruction, it was not comprehensively and coherently integrated into the curriculum in terms of planning and executing its use in an effective fashion. In that sense, teachers must be competent enough in the pedagogical use of ICT in class to maximize results.

It is important to recognize some limitations of the findings of this study. The given sample size was perhaps not sufficiently large and homogeneous, since participants came from various educational programs or majors of the university, which means that students of certain programs are likely to have communication skills of language more in line with the level examined. Also, the number of hours to instruct and practice the LLS in class was fewer than expected given the time constraints.

Finally, future research in the implementation of instructional content based on cognitive and metacognitive strategies will probably include a more extensive and probabilistic sample. Furthermore, the application of a diagnostic test to determine if the learner has the appropriate level of competence to undertake the study should be considered even though they are supposed to be competent enough given that they have been sharing and passing through several curricular courses up to this point of the expected English proficiency level. Besides, it would be wiser to have students just coming from one educational program. Also, a number of hours of LLS instruction or practice can be extended if adopted a hybrid or blended educational model which may be supported by a technological platform, so the curriculum can be expanded and students may be given the opportunity to increase their exposure to the lessons and/or tasks at home or away from the classroom. Probably, it will be desirable to determine a format of participant-observation of the researcher with a tool that allows obtaining weekly data about progress and the type of strategies more used by students. It would also be interesting to explore gender issues to see if there are significant differences in the use of such strategies.

\section{REFERENCES}

[1] Aghaie, R., \& Zhang, L. J. (2012). Effects of explicit instruction in cognitive and metacognitive reading strategies on Iranian EFL students' reading performance and strategy transfer. Instructional Science, 40, 1063-1081. DOI: 10.1007/s11251-011- 9202-5. 
[2] Alharbi, M. A. (2015). Reading Strategies, Learning Styles and Reading Comprehension: A Correlation Study. Journal of Language Teaching and Research, 6(6), 1257-1268. DOI: 10.17507/jltr.0606.13. Retrieved January 20, 2016, from http://www.academypublication.com/ojs/index.php/jltr/article/view/jltr060612571268/452.

[3] Battaglia, M. P. (2008). Nonprobability Sampling. In Encyclopedia of Survey Research Methods. Thousand Oaks: SAGE Publications, Inc., 523-526

[4] Burke Johnson, R., \& Onwuegbuzie, A. (2004). Mixed methods research: A research paradigm whose time has come. Educational Research, 33(7), 14-26.

[5] Chamot, A.U. (2004). Issues in Language Learning Strategy Research and Teaching. Electronic Journal of Foreign Language Teaching, 1(1), 14-26.

[6] Chellamani, K. (2013). Activating metacognitive strategies on enhancing reading skills among high school students. International Journal of Education and Science, 5(2), 159-162.

[7] Cohen, J. (1988). Statistical Power Analysis for the Behavioral Sciences (2nd edn). Hillsdale: Lawrence Erlbaum.

[8] Iwai, Y. (2011). The effects of metacognitive reading strategies: pedagogical implications for ESL/EFL teachers. The Reading Matrix, 11(2), 150-159.

[9] Kasimi, Y. (2012). Cognitive and metacognitive strategies employed by Iranian and Turkish EFL readers. International Association of Research in Foreign Language Education and Applied Linguistics, 1(3), 159-174.

[10] Lai, Y.-S., Tsai, H.-H., \& Yu, P.-T. (2011). Integrating annotations into a dual-slide PowerPoint presentation for classroom learning. Educational Technology \& Society, 14(2), 43-57.

[11] Lin, CH.-H., Yang, S.-CH., \& Lai, CH.-CH. (2013). Support as a mediator of the impact of cognitive load on students' e- portfolio learning outcomes. Social Behavior and Personality Journal, 41(1), 17-30. Doi:10/2224/sbp.2013.41.1.17.

[12] Lin, Z. (2002). Discovering EFL learners' perception of prior knowledge and its roles in reading comprehension. Journal of Research in Reading, 25(2), 172-190.

[13] Liu, O. L. (2009). Evaluation of a learning strategies scale for middle school students. Journal of Psycho-educational Assessment, 27(4), 312-322.

[14] Marzban, A. (2011). Investigating the role of multimedia annotation in EFL reading comprehension. Procedia Social and Behavioral Science, 28, 72-77. doi: 10.1016/j.sbspro.2011.11.015.

[15] Mokhtari, K., \& Reichard, C. (2002). Metacognitive awareness of reading strategies inventory (MARSI) Version 1.0. Retrieved April 23, 2014, from http://www.dayofreading.org/DOR10HO/MARSI_2002.pdf.

[16] Motallebzadeh, K., \& Mamdoohi, N. (2011). Language learning strategies: a key factor to improvement of TOEFL candidates' reading comprehension ability. International Journal of Linguistics, 3(1), 1-10.

[17] Nacera, A. (2010). Language learning strategies and the vocabulary size. Procedia Social Behavioral Sciences, 2, 4021-4025. doi: 10.1016/j.sbspro.2010.03.634.

[18] Nejabati, N. (2015). The Effects of Teaching Self-regulated Learning Strategies on EFL Students' Reading Comprehension. Journal of Language Teaching and Research, 6(6), 1343-1348. DOI: 10.17507/jltr.0606.23. Retrieved January 20, 2016, from http://www.academypublication.com/ojs/index.php/jltr/article/view/jltr060613431348/462.

[19] Oxford, R. L. (2003). Language learning styles and strategies: an overview. GALA, 1-25. Retrieved June 11, 2014, from http://ebookbrowse.com/language-learning-styles-and-strategies-oxford-doc-d216659522.

[20] Phakiti, A. (2003). A closer look at the relationship of cognitive and metacognitive strategy to use to EFL reading comprehension test performance. Language Testing, 20, 26-56.

[21] Pham, H. (2011). Theory-based instructional models applied in classroom contexts. Literacy Information and Computer Education Journal, 2(2), 406-415.

[22] Rahimi, M., \& Katal, M. (2011). Metacognitive strategies awareness and success in learning English as a foreign language: an overview. Procedia Social \& Behavioral Sciences, 31, 73-81. DOI: 10.1016/j.sbspro.2011.12.019.

[23] Ramírez, M. S. (2013). Production of Open Educational Resources [video]. Retrieved January 10, 2014, from http://apps05.ruv.itesm.mx/portal/uvtv/video/video.jsp?folio=2692.

[24] Sarica, G. N., \& Cavus, N. (2009). New trends in 21st century English learning. Procedia Social and Behavioral Sciences, 1(1), 439-445. DOI: 10.1016/j.sbspro.2009.01.079.

[25] Secretaria de Educacion Pública. (2006). Acuerdo por el que se determinan políticas, estándares y recomendaciones relacionadas con la enseñanza y certificación de lenguas extranjeras, así como del español como lengua adicional. Recuperado en Octubre 16, 2014 dehttp://www.cgci.udg.mx/sites/default/files/SEP\%20standards.pdf.

[26] Secretaria de Educacion Pública. (2016). Participación del secretario de Educación Pública, Aurelio Nuño Mayer, en la 99 Asamblea Anual de la American Chamber México. Recuperado en Marzo 20, 2016 http://www.gob.mx/sep/prensa/participacion-del-secretario-de-educacion-publica-aurelio-nuno-mayer-en-la-99-asambleaanual-de-la-american-chamber-mexico.

[27] Suwantharathip, O. (2012). The effects of reading strategies based on collaborative learning approach on EFL students' reading comprehension. European Journal of Scientific Research, 88(1), 11-27.

[28] Tashakkori, A., \& Teddlie, C. (2003). Handbook of mixed methods in social and behavioral research. California, USA: SAGE.

[29] Tezcan, S., \& Deneme, S. (2016). A Study on Language Learning Strategy Use of Young Turkish Learners. Journal of Language Teaching and Research, 7(1), 42-48. DOI: 10.17507/jltr.0701.05. Retrieved January 20, 2016, from http://www.academypublication.com/ojs/index.php/jltr/article/view/jltr07014248/533.

[30] Wichadee, S. (2011). The effects of metacognitive strategy instruction on EFL Thai students' reading comprehension ability. Journal of College Teaching \& Learning, 8(5), 31-40.

[31] Xu, X. (2011). The relationship between language learning motivation and the choice of language learning strategies among Chinese graduate. International Journal of English Linguistics, 1(2), 203-212. DOI: 10.5539/ijel.v1n2p203.

[32] Zare, P. (2012). Language learning strategies among EFL/ESL learners: a review of literature. International Journal of Humanities and Social Science, 2(5), 162-169. 


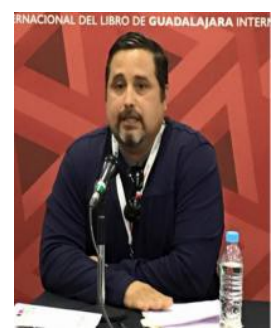

Miguel A. Ochoa was born in Hermosillo, Sonora, México, in 1973. He received his B.A. in Business Administration in 1997 from the Universidad de Sonora. Now he is a PhD candidate in Educational Innovation at Tec de Monterrey. He is teaching EFL courses at Universidad Estatal de Sonora. His areas of interest are language learning strategies, multimodal learning environments, action research and also reading comprehension.

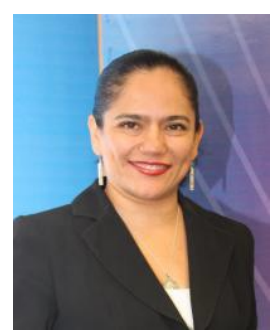

María S. Ramírez holds a doctorate in Philosophy and Educational Sciences from the University of Salamanca. Her research interests include teaching strategies, technology resources for education, training of educational researchers and open education movement. She works as a research professor at the School of Education, Humanities and Social Sciences of the Tecnologico de Monterrey (Mexico) in the master's and doctoral Education programs. She is director of the UNESCO Chair "Open Educational Movement for Latin America”, director of the International Council for Open of Distance Education (ICDE): OER Latin America office, lead researcher on the Strengthening Information Society Research Capacity Alliance (SIRCA) network, main organizer of the Regional Open Latin American Network for Social Research and Education (CLARISE) and coordinator of the Research and Innovation in Education Group (GIIE) at Tecnologico de Monterrey. She is a member of the National System of Researchers in Mexico. 